\title{
Auxiliary locomotion device to unload lower limbs, using user's own secondary support
}

\author{
Eduardo. J. W. Alves, Leandro. E. V. Melo, Sérgio. J. Silva, Jairo J. D. Câmara \\ CEMA/LAB-laboratory of Sensory and ergonomic Studies - University of the State of Minas Gerais - UEMG, \\ AV. Antonio Carlos, São Luis, postal code 7545, 31 270-010, MG, Brazil
}

\begin{abstract}
The systematic of device development for support in the period after surgery and for consolidation of fractures of lower limb, manufactured in aluminium alloy and PVC, integrated with quick fixes, cleanliness simplified, retractable, and adaptable to wide range of biotope. Has as value-added a possibility of transforming an axillary crutch in Canadian and, where necessary, the transformation of the Canadian crutch in cane to aid the balance and safety on return to walk independently. The proposed instrument enhances the limited movement capabilities and mobility by ensuring greater security and versatility of the beginning of the user's recovery until the end of his convalescence.
\end{abstract}

Keywords: design, adaptability, flexibility, biotype; mobility

\section{Introduction}

The crutches used for aiding in March and unload the user's own lower limbs, little has changed in the past two centuries. The development of a product based on the needs of the user, within the constraints of the market, in usage factors, in respect of materials, credits a value to the product that is perceived and evidenced as sales argument, expanding the market with quality product.

Usability, meeting the needs of users, the proper use of the materials, the unassemblyness and possibility of composition, are aspects that involve ergonomic factors in relation to human morphology and biotope, having also the purpose of meeting a representative range of possible users with distinct characteristics. Including relations imposed by age limitations, with the intention to serve a larger number of requirements imposed by differences and variables and object Relations/use/human body, and thus serve a greater number of users, including reduction of production costs.

\section{Goals}

Determine a set of essential conditions for optimization of auxiliary locomotion device, through intervention in the study of optimization of the product and help in social reintegration.

Survey of development characteristics of an auxiliary locomotion device which can meet the user throughout his recovery, so that it can transform, through substitution of accessories, in axillary crutch, Canadian or cane.

\section{Literature review}

The existent auxiliary device in the market, are found in multiple configurations, being used by persons who have suffered some trauma or have some difficulty of locomotion, permanent or temporary, needing during his recovery, which can be indefinitely, and that cannot unload their weight on the lower limb (s).

In Brazil, currently, more than 500 people become disabled each day, many have their problem aggravated when using this apparatus on erroneous 
way, for lack of guidance or by lack of available resources to fit the profile of the biotope of the user.

S. V. Fisher apud, A. P. Gaspar et al (2003). studied the energy expenditure in patients not amputees using crutches on flat ground and stairs; and concluded that the volume of oxygen (VO2) of these individuals reached $40 \%$ of maximum expected for the same and that the heart rate reached to $62 \%$ of the maximum set and therefore, that the use of crutches in heart disease patients should be done with restrictions. The energy expenditure during the march with axillary crutches is approximately two times higher when compared to a normal march. The purpose of this paper is to compare the energy expenditure in patients of lower limb amputees with use of the prosthesis and crutches

More attention, therefore, you should be given to integrating ergonomics product design. Ergonomics brings to the architectural design process a more systematic approach for analysis, the specification the evaluation of the usability requirements. Ergonomics brings knowledge and techniques that increase the ability of the designer to project interfaces with user's success (CID - Corporate Industrial Design, Philips apud A. Moraes, (19993: 365)

For Blaich apud A. Moraes, (1993: 364) ergonomics is an integrating part of the project and the Projection, whenever there is a product-user involvement. An appropriate product design requires interaction with the practice of ergonomics.

Majority of the products, mainly the most complex, has attributes that are critical to successful use by users. These attributes should be systematically identified, measured in terms of human performance requirements and, whenever possible, the results of these studies should be incorporated into the product design. Ergonomics has the capability to do this. (M. Pequini, 2005)

Ergonomics helps reduce suppositions and increases the level of reliability of the design decisions in regard to considerations of important factors of the users. (M. Pequini, 2005).

Blaich apud M. Pequini, (2005), States that there is no specific stage for the introduction of ergonomics in the development process of the project, because this can contribute at all stages.

Moraes apud M. Pequini, (2005) Note that the ergonomics applied to product development is a systematic that aims to create products that work well in human terms. Its focus is the user of the product, and its main objective is to ensure that the products are easy to use, easy to learn, productive and secure.

The conceptualization of the product involves the analysis of the allocation of functions between the user and the object in terms of capacity and limitations of user and user-specific general objectives. The main objective is to ensure that the needs of users and the product attributes should mold. Blaich apud M. Pequini, (2005).

The specification of the product assures that important usage requirements are incorporated into specifications for products. This may involve carrying out studies for the provision of relevant data/information. M. Pequini, (2005).

When it comes to the conception of products, for humans, the most important requirement, upon which we should not make concessions, is the user's safety. So it is of fundamental importance in the projectile act to consider, first, the human factors, and this requires a deep knowledge of the physical and psychological characteristics of human being. I. Iida apud M. Pequini, (2005).

\section{Development}

In the design of the variety and diversity of human features, requires the interaction of several disciplines and effective techniques in the effective product conception. A tool to help a locomotion of people unable to use their own lower limbs requires flexibility, simplicity and its cost of production should outline the breadth of benefices population that holds these special needs, enabling the achievement of a locomotion more comfortable with less muscular effort.

Among the complex development factors for this product are also the specification of the production process, aesthetic and sensory aspects involving the cognition and affect the self-confidence that arouses emotion, or repulsion, factors that can encourage the user or embarrass him, so as to encourage its reestablishment or impede its recovery.

Before considering in detail the various factors that relate to the human being with the work, is necessary to understand the part played by the human being. In any activity, a human being receives and processes information, decides to and realizes actions. The first recipient, function, occurs largely through the senses (eyes and ears), but the information can also be transmitted through 
kinesthetic. These information are transmitted through the nervous system to the central mechanism of the brain and spinal cord, where they are processed, and a decision may result. This processing may involve the integration of information being received with information that is already stored in the brain, and decisions can vary from automatic reactions to those that involve a high degree of reasoning or logic. Having received and processed the information, the individual will perform actions such as resulted by decision and will do so through its mechanism, which usually involves muscle activity based on the skeletal structure of the body. Palmer apud M. Pequini, (2005).

In the process of developing new products is of great importance to experimentation and testing, which are made through models and prototypes to check each value specified in the project requirements and in complying with the demands of users. When products are accepted through the identification of values, encourages interactions that complement the social get-together, contributing to the reestablishment of a healthy life.

The aspects of esteem influence decisions of choice in virtually all decisions we take, then, that the study of ergonomic aspects are no longer restricted to meeting the basic needs of the user, little interfering only on aspects that are directly related with resolution of use function, is necessary be thorough and detailed in the sensory aspects and cognition as the esteem, not only the tangible values, but in the same way, also the intangibles as the pleasure, the revulsion, the comfort, the beauty, in addition to the cultural and symbolic values that a product may pass through the elements of your set of shapes, colors and symbolism.

Similarly, the ergonomics, which addressed the issues between man/machine, today deals with the relationship man $/$ system $^{1}$, where all interactions that affect humans in the system that is inserted, such as environment, objects, work, relationships and interactions are related to ergonomics, including interaction with software, making it much more extensive and complex that comprehensiveness in

\footnotetext{
${ }^{1}$ Second HENDRICH, h. and KLEINER, b. m., is dealing with the analysis and design (design) of work systems. Systems refers to systems that sociotechnical, pointed out three elements to monitor technological subsystem: subsystem, and the staff of project work subsystems, which consist of the combination of an organizational structure and processes, and can be as simple as a single individual using a hand implement or as complex as a multi-national organization.
}

the recent past, If considered the beginning of the industrial age.

Today we find new horizons of knowledge to reduce losses and provide greater assurance of success and can reduce the need for interventions in our bodies, increasing assertiveness in its Diagnostics reduces treatment and convalescence time, however, nature still imposes limits for various aspects of human convalescence, as re-composition time of their tissues, as the case of many bone reductions $^{2}$ that require static convalescence, without the affected limb be exposed to the fatigue or to work.

The requirements of the project when it considers the whole extent of the problem, facilitates their understanding and inclusiveness, understanding their needs and constraints for the determination of a planning considering the whole system.

The determination of target public assists in decision-making objectivity during the various stages of product development, targeting problem resolution for more specific issues so as to better meet your needs from the identification of their customs and modus operantis, as is the case of active people who are always on the move and which has greater agility, usually mesomorfos ${ }^{3}$ and ectomorfos 4 , with characteristics of being restless, participate in various social activities, being in full productive capacity, so with different needs of sedentary people generally endomorfos ${ }^{5}$, less active and more reclusive than previous, but could benefit from the solutions found to benefit the previous group.

\section{Methodology}

I. Identification of components of the problem - existing devices.

II. Usage analysis.

III. Verification of data and the form of action for improvement.

\footnotetext{
2 Act of making back to his seat bones fractured or displaced.

${ }^{3}$ More people have the greatest pre-arranged muscle gains.

4 Person who has difficulty in acquiring large arms and legs, weight, small percentage of body fat and a few muscles.

${ }^{5}$ People pre-arranged a greater accumulation of fats.
} 
IV. Determination of ergonomic solutions defined for industrial application.

V. Indication of constructive shapes - project templates/prototype.

VI. Indication of restrictions to be applied

\subsection{Identification of components of the problem - existing devices.}

The development of a new product start at the detection of a problem or an opportunity, both has the connotation of being problem and opportunity at the same time, changing according to the paradigm to observe. From that identification is necessary to raise the issues related to product, elaborate research, observe the problem in action, their use, inconvenience, advantages and disadvantages, human/object interaction, improvisations and, which has not yet been met. Is it necessary to hear users and professionals linked to the fact about, needs, constraints and propositions that can append values not yet identified. In the case of crutches, identify the types of needs, organizing them into groups, axillary, Canadian and also the cane with its variations of up to four support points.

\subsection{Analysis of the use of auxiliary device.}

The systematic observation of the modus operandis the product, added to the guidelines of medical needs and restrictions diagnosed by medicals, therapists, physical educators and researchers of the subject, added to survey of needs and constraints relating to the displacement of the users in the various types of environment, the differentiated needs of the various social and cultural tracks, plus tangible and intangible values detected helps guide the development of the problem in such a way as to meet the user beyond their perceived needs.

\subsection{Verification of data and the form of action for improvement.}

From the identification of a series of relevant data that has interactive participation in the issue, it is necessary to identify and scale by priority the main needs, its restrictions, propositions and opportunities most relevant to consider for the user profile described so as to reduce interference caused by this tool that will interact with the user in his daily routine for a period of time.
Identify the advantages of materials compared to others, to weight, strength, texture, easiness of being processed, of finishing and maintenance, be bactericide, fungicide and/or have availability, and cost still befitting the benefits, among other features. In what cases auxiliary devices are required for locomotion? There is a distinction needs to be considered? What factors are important to safeguard the affected areas? Which requirements are important during locomotion to soften muscle strain? Which efforts should be avoided? Which pattern must be printed on the motion? What level of muscular work exercised in different situations of walking, like climbing ramp or descend stairs? These are some questions that help to structure the project and focus it on the needs and expectations of users.

\subsection{Determination of ergonomic solutions defined for industrial application.}

Even in the choice of materials, the observation of ergonomic aspects are as important as determining the ergonomic shape to be set in the grip of a tool. The material is related to the production process, the environmental impact caused by their exploitation and by his disposal, physical endurance, elasticity, specific weight, perceived weight, composition, how it interacts in parts where there will be contact with the body, texture and thermodynamics perceived in contact, the body fluid reaction interacting with the material, the aspect that must be perceived by the user to transmit resistance, security, cleanliness, and the same sensations of pleasure to the touch. What aspects will have the best features to meet the complexity of the needs identified, with the available technology and price compatible to proposal.

This entire process has the human being as the central point, where each decision has the focus directed to him, to his territory, his safety and integrity and sustainable development.

Industrial design works with an organizational system that initiates from research and observations for the search of optimal solutions to the problem, analyzing the macro context in which the issue belongs, to solve it centered on the needs and constraints of the client and user within the constraints imposed by the system, interfering in the entire process of industrial, commercial and distribution. According to Hendrick and Kleiner 
(2006 p. 19), "while the ergonomics has its focus in the design of work systems, to fit people, organizational psychology is primarily concerned with adjusting the people to the systems of work", as occurs with projects product-centered.

In macroergonomy, as well as in the design, the organizational system should involve the whole system that the problem is involved for the search for an optimal solution. Hendrick and Kleiner (2006 p. 9) cites that "A macroergonomy is dealing with the analysis and the project (design) of systems of work (the work term used generically to refer to any form of activity or human effort). Systems, refer to sociotechnical systems. [...] Sociotechnical systems points three elements to monitor in this process: the technological subsystem, the personnel (staff) subsystem, and the project of work subsystems, which consist of the combination of an organizational structure and processes that interact with each other and with the external environment, of which the Organization depends on for survival and success ".

The methodologies used in design project come up refining to meet not only the basic needs of individuals as though honing to meet increasingly their feelings and emotions in the performance of its basic tasks as well as for the development of solutions to ameliorate the work making it the most pleasurable diving, for the improvement of communication and interactions. Pursue new technologies as they propose the ergonomics, making these two disciplines melt with all its interfaces in order to build sustainable values.

Second I. Itiro (2005 p. 324) "... the contribution of the ergonomist ( to design project) begins with the definition of product specifications, and continues during all stages of development and reaches the final stage of evaluation of the product in use". Increasingly the designer incorporates the ergonomics for the pursuit of design solutions that will meet the users without the commitment of their physical integrity and way benefit, engage and leverage the senses in human relations/system.

\subsection{Indication of constructive shapes of project - templates/prototype.}

As universal project the development of this device search a series of principles for his guidance to be applied on models and prototypes:
Alignment: ensure that the goals of different participants are aligned.

Application of force: the use of crutch requires a human effort exercised mainly through the arm muscles (biceps ${ }^{6}$ and triceps ${ }^{7}$ ), passed on to the forearm, distributed by the wrist and passed to the hand.

Cleanliness: for-see the selection of materials, in the definition of forms and fittings, in the texture and finding of different materials is ease of product hygiene and safety to user as opposed to the accumulation of dirt.

Assemblyness: planning so as to provide the possibility to compose the product with accessories that meet user needs.

Cost: Identification of materials, technologies and production processes that allow the reduction of production cost by increasing the base of use of the product.

Un-assemblyness: product planning so that can be unfolded to facilitate transportation, maintenance and parts replacement foreseeing compositions of settings.

Emotion: are the assumptions that the product has a meaning beyond the utility, picked up by details and nuances that make up the product typology, the harmony of shapes, colors, texture, providing pleasure in use relation.

Wrap physical range: usage analysis, sensory and comfort for the scaling of the user relationship/product. User interface configurationgrip, user-support arm and axillary reference-user.

Involvement: involve the user in the experiences of development so as to provide him with the authentic feel genuine and captivating of usage.

Appropriate Space: prediction of dimensional reduction and un-assembly of the product in order to facilitate its transportation in vehicles and at places that may need the reduction to promote interactions and reduce interference in the environment.

Popular Stereotypes: formed by the set of byproducts that require some operational actions and management control, showing aspects of stereotyping. Some obvious and practiced for more

\footnotetext{
${ }^{6}$ Muscle with one end split into two separate muscular bodies.

7 Triceps brachii is a broad skeletal muscle of three heads.
} 
than a century, such as: height adjustment by means of screw-butterfly. Be built in wood, relying on the crutch through armpit.

Flexibility of use: the product includes several configuration possibilities and complementarities, adapting to users ' preferences and restrictions.

Perceptible Information: provide an objective reading of the product so that people can understand and use its functions and features without relying on special skills.

Evolutionary Innovation: enable engage and adapt a product so that the user can adapt the product to its needs at a lower cost and as a result, to extend the offer to a wider population and more directions. Satisfy unmet needs enabling adaptations to specific needs.

Posture: The user's attitude is related to the adjustment of the height for the axillary crutch, throttling height and arm support guide for Canadian crutch, mode of moving the body to initiate motion, the position of the head during the motion, the use of the support leg, handling apparatus and pace employee at motion.

Reduction of energy expenditure: prediction of materials of low weight and resistance to consistent performance required, use of adjustments to suit users ' needs, avoiding static contractions of the muscular system, reducing the possibility of stress.

Responsibility: ensure the responsibility of companies by the impact of its products, one our bodies, our culture and our environment.

Noise: during the material selection and planning of fittings, couplings and connections, foresee for the possibility of friction noise or incompatibility of materials, so it doesn't happen.

Signs and Visual codes: signs convey the strong ability of insight for the information society in which we are inserted. Is the assignment of meanings to the recognition of something and to promote communication between people, people and objects and people and the environment, helping to organize and tailor the information that is streamed.

Synesthesia: realize the muscular movements, knowledge or movement of body parts to obtain information that will require the least effort of muscles, tendons and joints during a motion with the use of aid, with the aid of visual track and through technological devices such as the "eletromiógrafo" and the Matlab software that monitor muscle reactions subjected to efforts.

Sustainability: force for the use of materials and production processes of low environmental impact, both for its extraction, handling, transportation, production, processing, distribution, storage and disposal.

Error tolerance: development of models, prototypes and tests that may reduce the risk and on the possibilities of adverse consequences of accidental or unintended actions. Therefore predict in a logical way and easy to access the adjustment controls, so that the settings are accurate and remain secure throughout its use, accidental or unintentional reversal protection settings, allowing the possibility of new combinations. Providing usage manual and warning discouraging unsafe actions by warning of the possibility of errors that can be detected.

Usability: planning of use of the product in the different phases of convalescence and user's ease of adjustments to human interaction-object be more harmonic and intuitive, requiring minimal effort to carry out the tasks.

Fair Use: predicting dimensions, adjustments, and accessories that allowing its use in a similar manner by all users, expanding the use of the product base.

Using simple and intuitive: so as to provide a straightforward, easy to understand interaction through simple features.

Vibration and adjust: balance, oscillation or trepidation provided by materials selection or by failure at the joints, joints and fittings that can influence the balance of the user.

\subsection{Indication of restrictions to be applied}

The sum of project guidelines described above, for decision-making, aligned to the requirements necessary for the various components of the products of three devices in question, axillary crutch, Canadian crutch and cane can interact for formation of distinct products through the combination of components, which should meet the needs of the user, during his convalescence phase.

- Base module - that meets three devices;

- Axillary module top - connected to the base module acquires axillary crutch configuration. 
- Canadian module - connected to the base module acquires Canadian crutch of configuration.

- Cane module - connected to the base module acquires the configuration of a cane. The Basic module can be composed of a variable four needles, simple, needle nozzle forked, triple or four support points, to meet the diverse needs already identified.

Project requirements, must also meet the following criteria:

- Easy connection components;

- Easy adjustment;

- Easy replacement of components;

- Ease of separate components of different materials;

- Secure connections;

- Not provide trepidation of components

- Avoid the possibility of any component move without the user's decision (adjustments which cause insecurity);

- Locking systems for tuning systems;

- Needles anti-impact and anti-slip

\section{Conclusion}

The development of this research will surprise us in many ways than verification of the proposed objectives, because it is an investigation that began with a simple purpose, but involve complex factors such as psychoacoustics, physioacoustic analysis of sounds, behavior, environment, processes production, ergonomics, physical, biodesign, medicine and engineering, among others.

In addition to encouraging the diversity of opportunities to identify facts that this research presents the specific objectives in the signal for the development of a methodology for measuring and identifying sounds that can also act as a tool to support sustainable actions when identify structural problems through the sounds, and thus enables a new way to boost identify and correct operational problems in chairs so you can fulfill its function again without harming people physically and psychologically.

\section{References}

[1] B. B. Mozota; C. Klöpsch; F. C. Costa. Design management: using design to built brand value and corporate innovation. Porto Alegre: Bookman, 2011.

[2] C. Belchior. iPhone: object of desire. Belo Horizonte: ed. The author, 2008.

[3] D. A. Norman. Design of the future. Rio de Janeiro: Rocco, 2010.

[4] D. Sudjic. The language of things. Rio de Janeiro: Intrinsic, 2010.

[5] F. Guérin; A. Laville, F. Daniellou, J. Duraffourg, A. Kerguelen. Understand the work to transform it - the practice of ergonomics ... São Paulo: Blucher, 2001.

[6] G. Vassão. Metadesign: tools, strategies and ethics for complexity. São Paulo: editora Edgard Blücher, 2010.

[7] Gaspar a. p. et al. Energy expenditure in amputee patient with transtibial prosthesis and crutches. Acta fisiátrica 10 (1): 32-34, 2003

[8] H. Hendrick, B. M. Kleiner. Macroergonomy: an introduction to system designs. Rio de Janeiro: Editora Virtual scientific, 2006.

[9] H. A. Couto. Deploying ergonomics in the company: the practice of ergonomics committees. Belo Horizonte: Ergo, 2002.

[10] H. Irigari et al. Management and development of products and brands. Rio de Janeiro: FGV, 2004.

[11] H. Rozenfeld et. al. Product development Management: a reference to the improvement of the process. São Paulo: Saraiva, 2010.

[12] I. Iida. Ergonomics - design and production. São Paulo: Blucher, 2010

[13] J. G. Son. Ergonomics of the object: ergonomic reading technical system. São Paulo: Scriptures, 2003.

[14] J. Lesko. Industrial Design: materials and manufacturing processes. São Paulo: Blucher, 2004

[15] J. Panero; M. Zelnik. Las dimensiones estándares in human losespacios interiors: anthropometric. Mexico: Edimex, 1984.

[16] K. H. E. Kroemer and E. Grandjean. Ergonomics Manual: adapting the work to the individual. Porto Alegre: Bookman, 2005.

[17] M. Baxter, Product design - practical guide for the design of new products. São Paulo: Blucher, 2008.

[18] M. Dijon. Meta: the design of design. São Paulo: Edgard Blücher, 2010

[19] P. C. Dinsmore and F. H. Grandson. Project management: how to manage your project with quality, on time and expected costs. Rio de Janeiro: Qualitymark, 2004.

[20] P. Kotler. Marketing 3.0. the forces that are defining the new marketing. Rio de Janeiro: Elsevier, 2010.

[21] Rosa, J. G. and A. Moraes. Assessment and design in the design of interfaces. Teresópolis: 2AB, 2008.

[22] S. M. Pequini. Ergonomia aplicada ao design de produtos: Um estudo de caso sobre design de bicicletas. Universidade de São Paulo - Faculdade de Arquitetura e Urbanismo, 2005.

[23] T. Brown, and B. Katz. Design Thinking: a powerful methodology to make the end of old ideas, Rio de Janeiro: Elsevier, 2010.

[24] T. Kelley. The 10 faces of innovation: strategies to about boosting the creativity. Rio de Janeiro : Elsevier, 2007.

[25] Z. Bauman. Life for consumption: the transformation of goods. Rio de Janeiro: Zahar, 2008. 